\title{
Urgences
}

\section{Notes biographiques}

Numéro 12, 3e trimestre 1984

Spécial humour

URI : https://id.erudit.org/iderudit/025192ar

DOI : https://doi.org/10.7202/025192ar

Aller au sommaire du numéro

Éditeur(s)

Urgences

ISSN

0226-9554 (imprimé)

1927-3924 (numérique)

Découvrir la revue

Citer ce document

(1984). Notes biographiques. Urgences, (12), 84-85.

https://doi.org/10.7202/025192ar

Ce document est protégé par la loi sur le droit d'auteur. L'utilisation des services d'Érudit (y compris la reproduction) est assujettie à sa politique d'utilisation que vous pouvez consulter en ligne.

https://apropos.erudit.org/fr/usagers/politique-dutilisation/
Cet article est diffusé et préservé par Érudit.

Érudit est un consortium interuniversitaire sans but lucratif composé de l'Université de Montréal, l'Université Laval et l'Université du Québec à Montréal. Il a pour mission la promotion et la valorisation de la recherche. https://www.erudit.org/fr/ 


\section{NOTES BIOGRAPHIQUES}

DOMINIQUE DE PASQUALE. Écrivain, dramaturge, journaliste et administrateur, né en 1946 à Montréal. Ses principales pièces de théátre: "Moa" au Théâtre des ApprentisSorcières en 1967, "L'arme au poing ou larme à l'oeil" a représenté le Québec au Festival International de théátre de Monaco en 1969 (Leméac), "Oui, chef" premier prix du concours de la Nouvelle Compagnie Théâtrale en 1970 (Leméac), "On n'est pas sorti du bois", également en version anglaise pour le Canada (Leméac). Plusieurs textes dramatiques ont été diffusés à la radio et à la télévision. Parmi eux: "Le roi ou le valet" créé à la Radio Suisse Romande. Également créé sur les mêmes ondes, le conte radiophonique "Un Noël pour Giovanna". Dominique De Pasquale a en plus collaboré aux émissions "Micro-théâtre", "Premières", "Scénarios", "Moitié-Moitien et aux séries "You-Hou", "Tam-Tam" et "Pop-Citrouille". Il a publié chez HMH, avec Ginette Laurendeau, une série de livres pour enfnats: "Marc et Mathilde". Actuellement il est le rédacteur en chef de la revue "Les Diplómés" de l'Université de Montréal. Membre de la S.G.D.A., de la SARDEC, de CAPAC et de I'UNEO.

GILBERT DUPUIS. Est originaire de la Gaspésie. C'est d'ailleur de cette région qu'il a recueilli l'épisode savoureux qui est publié dans ce numéro. En plus du style narratif employé ici, l'auteur a abordé la poésie, le monologue, le conte pour enfants, la nouvelle et, depuis quelques années, le roman. II a publié jusqu'ici La tête dans le crin (Passages). Le cheval de l'lle St-Bamabé et La chamado d́octrique chez Éditeq. Il a de plus collaboré aux revues Estuaire, Osiris et Urgences $(1,4.6,10)$. En plus d'écrire, Gilbert Dupuis a oeuvré et oeuvre toujours pour la reconnaissance et le rayonnement de la littérature est-québécoise. On a pu le voir au sein du Regroupement des Auteurs de l'Est du Québec, au comité de direction d'Urgences et, actuellement, à la maison d'édition coopérative de l'Est du Québec, Éditeq. II est membre de l'U.N.E.Q.

ALAIN ST-YVES. Joseph/Alain St-Yves, fils de Wellie et Espérance, est né à Louiseville en 1951 presqu'en méme temps que la grève du textile.

A fait des études fragiles à Trois-Rivières et à Montréal. A également fait à la même époque l'école buisonnière.

Deuis 1976, fait de son mieux au cégep de Gaspé. II continue d'apprendre. 
Vit à l'Anse-aux Cousins depuis 1977 après avoir passé 1 an dans la Petite France, quartier charmant de la ville de Gaspé.

Publiait vraiment trop rapidement en 1980 un premier bouquin: Cahier Brouillon grâce à la générosité d'une centaine d'amis/es appelés éditeurs éphémères improvisés.

Publiait aux mêmes éditions en 1984 (avec deux ans de retard cette fois) un second livre: Transparole en collaboration avec Marius Jomphe (illustrations) et Jacques Gratton (photographies). Si vous désirez ces deux volumes, vous pouvez les commander directement chez l'auteur.

A également publié des textes très spontanés dans les numéros 1 et 3 de la revue URGENCES. Par la suite, l'auteur insatisfait retravailla certains de ces textes. Quelquesuns furent même éliminés. La vie littéraire est ainsi faite.

Actuellement, travaille tranquillement à d'autres choses. Ne sait pas exactement où ça le conduira. Aimerait peut-être s'essayer dans un roman. Ses chats semblent en savoir davantage mais n'ont pas voulu en dire plus.

Les textes de la série "Poules et coqs", inspirés d'un jeu d'enfance qu'il jouait avec ses frères (faire des mots à partir de "pie") ont été pondus entre 1982 et 1984.

\section{Pour consommation rapide!}

JEAN-YVES DUPUIS. Est originaire de Trois-Pistoles. II a collaboré à l'émission L'atelier des inédits de Radio-Canada et a publié chez Moebius dans son treizième numéro. Urgences a déjà publié de ses textes dans ses numéros 4, 5, 9 et 11. Son premier roman intitulé Vivement la vie a paru à l'automne 1984 chez Pierre Tisseyre. Jean-Yves Dupuis reste fidèle à son style où l'humour, l'ironie et le quotidien font bon ménage.

JEAN COSSETTE. est originaire de Shawinigan. Il a vécu surtout à Montréal où il y a fait ses études en littérature et en psycho-éducation. Il vit depuis 1976 dans la Vallée de la Matapédia où il enseigne. Auteur d'un recueil de poésie, Le Transit des Fées et d'un conte pour enfants, Les petits soleils de Val-Brillant, tous deux publiés chez Éditeq en 1983 et 1984, il s'intéresse également à la dramaturgie. II a signé les pièces suivantes: Les rendez-vous du Café Inn (1981), Le retard ne s'attend plus (1982), On va avoir l'air des vrais fous (1982, modifiée en 1984) et Thérapie (1985). Il a diffusé des textes aux émissions Alternance et Au clair de la plume de Radio-Canada. S'intéressant à la mise en scène, il en a signé neuf depuis 1978 en plus d'avoir adapté pour la scène La légende de John Frederick Darwall d'après le livre A diable-vent de Hélène Gauthier-Chassé (Éditions Quinze). Jean Cossette est membre du C.E.A.D. et de I'U.N.E.Q.

SUZANNE LAVOIE. A fait ses études élémentaires à Rimouski avant de partir vers la vieille capitale pour se spécialiser notamment en lettres, en musique, en arts, en Service social. Ses études universitaires se sont déroulées à l'Université Laal. Auteure engagée, elle signe des textes puissants et non-dépourvue des qualités propres à notre société en pleine révolution sociale où les rapports homme-femme se précisent et se clarifient. Suzanne Lavoie a déjà participé au numéro 10, "spécial fantasmes" d'Urgences avec un texte intitulé " $F$ " pour... " $F$ ".

KARINE BARRIAULT. Avec ce spécial-humour, Urgences a choisi de présenter les textes de cette jeune auteure de Caplan. C'est en quelque sorte un ban d'essai et une excellente occasion d'exposer quelques facettes de l'humour tel que conçu par les enfants, un humour candide, très imagé et surtout, délicieux. 